Edited by Allan Beveridge, Femi Oyebode and Rosalind Ramsay

\section{Forensic Mental Health} concepts, systems, and practice

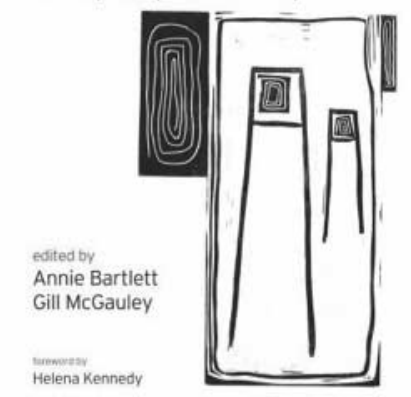
and Practice
Forensic Mental Health: Concepts, Systems,

Edited by Annie Bartlett \& Gill McGauley. Oxford University Press. 2009 £34.95 (pb). 448pp. ISBN: 9780198566854

New books do not emerge frequently in the field of what has come to be known as forensic mental health. I approached this one with some uncertainty in the light of its seemingly rather expansive subtitle. I need not have worried. Indeed, I should have known better given the editors and contributors (the foreword is by Baroness Helena Kennedy). Do not be taken in. The content is much wider and the book is both fresh and refreshing. It needs to be explored actively, otherwise one might miss something.

Reviews that simply list content can be dull. However, in this case it is important to do just that to describe at least some of the range of material covered. The book has six sections: Violence and Dangerousness, Forensic Psychotherapy, The Law, Ethics, Social Policy and International Perspectives. The content is strong throughout, particularly in relation to social, cultural and gender issues in the first section, introduced through a discussion of the medical model, anti-psychiatry and psychiatry as an institution. Someone with little or no knowledge of, or prior exposure to, the field could start right here. The same is true of the chapters on forensic psychotherapy and ethics, while retaining the sophistication that one would expect considering their authors.

I would venture to suggest also that anyone contemplating research into violence, even on a modest scale, should read at least the two chapters on criminological approaches to violence and its relationship with mental disorder. The section on the law is succinct and avoids the tendency to just catalogue sections of the relevant Acts. It gives clear guidance to those coming newly to the courts as well as offering insights to the more experienced. Again, the social policy chapters, centred on the development, in its widest sense, and delivery of services, describe, and perhaps more importantly reflect upon, the ever-changing landscape. Even the international perspectives, which can, when included, seem to be an afterthought, here are relevant, helpful and interesting to read. The concept of the 'sliding scale' of responsibility, or rather lack of it, and its origins, which may be considered in any case before the Dutch courts is fascinating. All chapters have stated aims, learning objectives and conclusions, and are well referenced so they meet the requirements of modern-day learners.

This is a book for Masters-level students or postgraduate trainees. It will also be of immense value to established

practitioners. For interested undergraduates from all the allied disciplines it will only serve to fuel their enthusiasm.

Martin Humphreys Senior Lecturer in Forensic Psychiatry, University of Birmingham, and Birmingham and Solihull Mental Health NHS Foundation Trust, Hillis Lodge, Hollymoor Way, Northfield, Birmingham B31 5HE, UK. Email: martin.humphreys@bsmhft.nhs.uk

doi: 10.1192/bjp.bp.110.084509

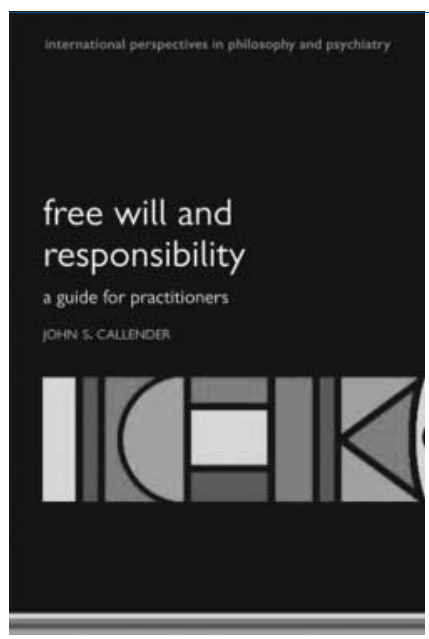

\section{Free will and Responsibility:} A Guide for Practitioners

International Perspectives in Philosophy and Psychiatry series By John S. Callender.

Oxford University Press. 2010.

£39.95 (pb). 408pp.

ISBN: 9780199545551

This book is a real treat. John Callender offers an engaging and rigorous account of how science and morality meet, addressing important issues which should be thought about and discussed well beyond academic circles.

In the first part, 'Thinking about morality', Callender tackles the following questions: how did morality evolve? Which role do emotions play in moral decisions-making? On what grounds is punishment for wrongdoing justifiable? Many of the scientific studies that have made an impact on thinking about morality and moral responsibility are described, their results assessed, and their implications explored. For instance, Haidt's social intuitionism model and Libet's studies on the causal (in)efficacy of conscious decisions are discussed at length. The main theories in moral and political philosophy are presented fairly, compared and challenged on both conceptual and empirical grounds. That is why this is not just a great prelude to what comes next, but also a useful and comprehensive introduction to ethics in its own right.

In the second part of the book, 'Thinking about free will', the reader appreciates more of Callender's own original thesis that the philosophical and practical problem of free will and moral responsibility can be enlightened by considering the role of spontaneity and creativity in art. The initial sections are a good critical summary of the literature on the alleged conflict between determinism and free will, and the implications that different solutions to this conflict have for moral responsibility and for reward and punishment. The later sections are where the author develops his idea that art and morals overlap and that moral judgements have a lot in common with aesthetic judgements.

The third part, on clinical applications, helps the reader apply the previous discussion to concrete cases of normal and pathological 'lack of freedom'. One chapter is dedicated to psychopathic personality disorder, one to trauma and dissociation, and one to the several dimensions of psychotherapy. 
The book is informative and thought-provoking. The author's most interesting suggestion about the notion of free will is that, by choosing to act in a certain way, we create ourselves.

The following quote aptly summarises what makes action free and autonomous for Callender: 'One way in which we can utlize our creativity is in generating models of our futures, which allow us to achieve lives in keeping with our desires and capacities. These models then become one of the causal factors that determine the decisions that we make about our lives' (p. 209).

Lisa Bortolotti Senior Lecturer in Philosophy, School of Philosophy, Theology and Religion, University of Birmingham, Edgbaston, Birmingham B15 2TT, UK. Email: I.bortolotti@bham.ac.uk

doi: 10.1192/bjp.bp.110.084483

\section{MICHAEL MOSKOWITZ}

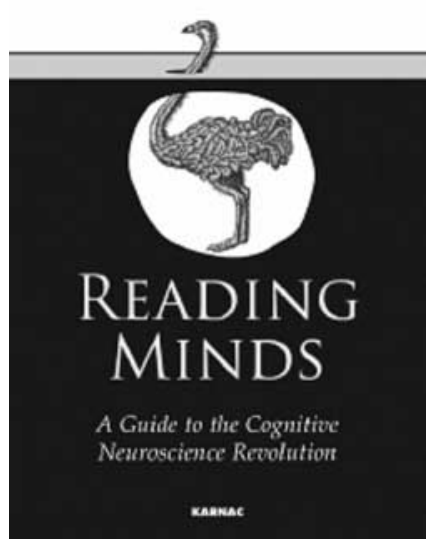

Reading Minds: A Guide to the Cognitive Neuroscience Revolution

By Michael Moskowitz. Karnac Books. 2010.

f19.99 (pb). 256pp.

ISBN: 9781855757141

Moskowitz, a psychoanalyst and organisational consultant, promises a great deal having captured our attention with his title, and he manages to deliver. Through his engaging, casual and accessible style, with stories from daily life, the clinical arena and the laboratory, Moskowitz will succeed at informing, provoking and entertaining the lay reader, although his scholarly rigour will also make this book appealing to clinicians and academics. He effectively brings together the theory and practice of a range of disciplines in a refreshing way, making them comprehensible even to the untrained reader, a skill seldom displayed in this field. His experience working in a variety of settings, clinical, organisational and academic, is evident in his work as he seamlessly blends concepts from different schools of thought.

This is, in fact, what he sets out to do in his introduction: an 'attempt to bring together and to connect what (he) can of this vast new field . . to better understand human nature'. Essentially, he aims to provide a practical guide to the cognitive neuroscience revolution and demonstrate how to use scientific principles to improve our understanding of and relationship with others. Of course, it is over a hundred years since Freud outlined his wish to integrate knowledge of the brain with evolving concepts of mental functioning. Moskowitz draws on ideas from developmental psychology, learning theory, neurobiology, anthropology and linguistics, to name a few. The book contains pictures as well as case studies. Of particular note is the discussion of Bill Gates' mindreading skills and the theory Moskowitz suggests as an explanation of Gates' success.
My only criticism is that there are a number of typographical errors within the text, but overall, this is an exciting book, written with boundless enthusiasm - a joy to read.

Hassan Kapadia ST6 in Psychotherapy, Cleveland House, 10/12 Tettenhall Road, Wolverhampton WV1 4SA UK. Email: hkapadia@doctors.org.uk

doi: 10.1192/bjp.bp.110.084467

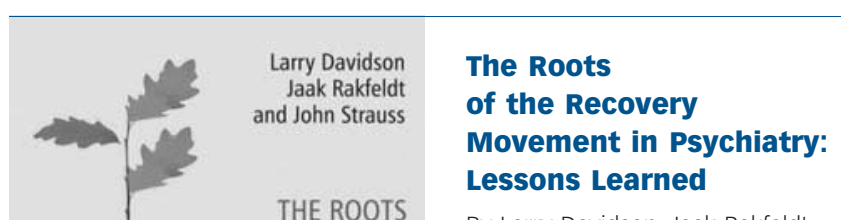

By Larry Davidson, Jaak Rakfeldt \& John Strauss. Wiley-Blackwell. 2010 £45.00 (hb). 294pp. ISBN: 9780470777633

Many have seen the current recovery movement, with its emphasis on personalisation, social inclusion and choice, as having arisen from earlier civil rights and disabilities movements. Here is a book that substantiates that claim through a succession of biographical sketches of innovators and activists of the past couple of hundred years.

Davidson and his colleagues have engagingly illustrated the continuity and progression of 'values in action' through the lives of people who have become our inspirational forefathers. Starting with Pinel, who inaugurated both moral treatment and the modern psychiatric era, they go on to social activists, Dorothea Dix and Jane Adams, pioneers of deinstitutionalisation, Erving Goffman and Franco Bassaglia, crusading civil rights and race leaders, including Martin Luther King, humane psychiatrists, Adolph Meyer and John Strauss and finally psychological and economic theorists, Lev Vygotsky and Amartya Sen.

Most of these names are familiar to even a casual student of the history of psychiatry but here is an opportunity to appreciate that nobody gets it right completely and to focus on what lessons can and should be carried forward as well as to underline cautionary notes concerning what we should avoid repeating.

However, it is initially puzzling that in a book dedicated to the roots of the recovery movement none of those reviewed specifically espoused 'recovery' as we currently know it. The authors could have written to their title by offering an annotated who's who of more recent recovery champions. Instead, they have offered something more profound and helpful by tracing the guiding principles of recovery back through various forms of emancipatory humanism and values-led activism which has fuelled progressive change throughout the modern era.

This inspirational and supportive book concludes with an imagined conversation between those reviewed. Having drawn the reader into this challenging conversation as a witness, the authors conclude by sending him out to continue the debate with friends and colleagues but certainly better equipped. 